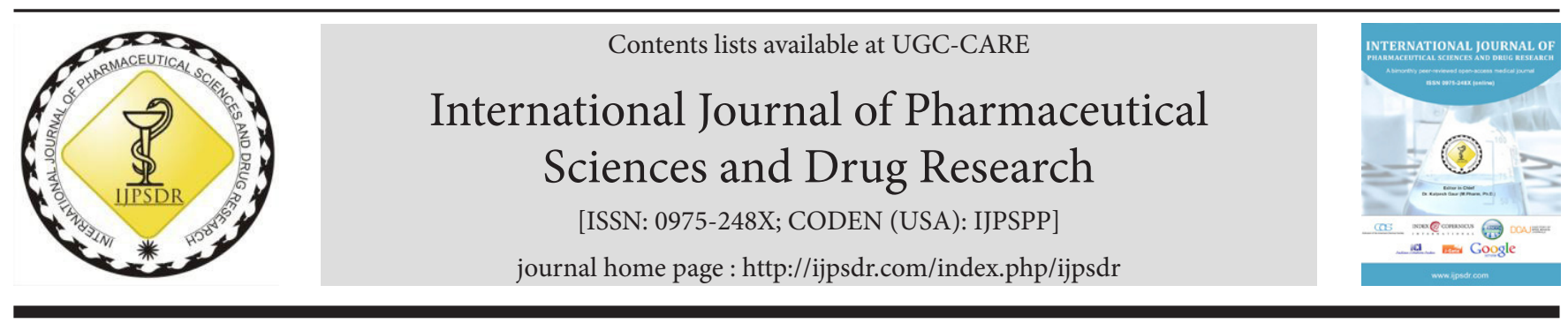

Research Article

\title{
Molecular Docking Study of Quinazolin-4(3H)-One Derivatives against GABAa Receptor Signifies the Novel Approach to Epilepsy Treatment
}

\author{
Surajmal Malpani*, Pradeep Kumar Mohanty, Ashish Jain \\ School of Pharmacy, LNCT University, Bhopal-462042, Madhya Pradesh, India
}

\begin{tabular}{l} 
A R T I C L E I N F O \\
\hline Article history: \\
Received: 17 July, 2020 \\
Revised: 21 August, 2020 \\
Accepted: 28 August, 2020 \\
Published: 30 September, 2020 \\
Keywords: \\
Diazepam, Epilepsy, \\
GABA, Molecular docking, \\
Quinazolinone. \\
DOI: \\
10.25004/IJPSDR.2020.120521
\end{tabular}

\section{INTRODUCTION}

Epilepsy is one of the most common neurological disorders, affecting about $1 \%$ of the world's population and characterized by recurrent seizure attacks. Antiepileptic drugs are neither preventive nor curative and are employed solely as a means of controlling symptoms. They can directly affect ion channels or indirectly influence synthesis, metabolism, or function of neurotransmitters or receptors that control channel opening and closing. For the simplest understanding of antiepileptic drug mechanisms, they fall into several general categories: the main groups include sodium channel blockers, calcium current inhibitors, GABA enhancers, and glutamate blockers. ${ }^{[1,2]}$

These drugs have proven to be effective in reducing seizures, whilst their therapeutic efficacy is overcome by some undesirable side effects, such as, drowsiness, ataxia, gastrointestinal disturbance, gingival hyperplasia, hirsutism, and megaloblastic anemia. In addition, about $30 \%$ of patients are refractory to these treatments. In view of the above observations, there is an urgent need to find new anticonvulsant compounds with more selectivity and lower side effect profile.

The development of heterocycles as scaffolds, containing a high degree of diversity has become a leading focus in modern drug discovery. Certain possible modifications to the heterocyclic ring by the addition of diverse substituents may lead to new products with better pharmacological profiles. Nitrogen heterocycles are among the most privileged molecular scaffolds of pharmaceuticals, in which quinazoline is an important milestone that is present in a total of nine US Food and Drug Administration (FDA) approved pharmaceuticals. ${ }^{[3]}$ One of

\footnotetext{
${ }^{*}$ Corresponding Author: Surajmal Malpani

Address: School of Pharmacy, LNCT University, Bhopal-462042, Madhya Pradesh, India

Email $\square$ : shethaji@gmail.com

Relevant conflicts of interest/financial disclosures: The authors declare that the research was conducted in the absence of any commercial or financial relationships that could be construed as a potential conflict of interest.

Copyright (c) 2020 Surajmal Malpani et al. This is an open access article distributed under the terms of the Creative Commons AttributionNonCommercial-ShareAlike 4.0 International License which allows others to remix, tweak, and build upon the work non-commercially, as long as the author is credited and the new creations are licensed under the identical terms.
} 
the most important quinazoline families is quinazolinones, which are the key scaffold components of approximately 150 naturally occurring alkaloids and drugs. ${ }^{[4]}$ Several reports have documented the biological activity of quinazolinones derivatives, including CNS related disorders, such as, convulsion, anxiety, ${ }^{[5-9]}$ antiinflammatory, analgesic, ${ }^{[10-13]}$ antiviral, ${ }^{[14]}$ antitumor, ${ }^{[15-17]}$ and antimicrobial. ${ }^{[18]}$

Although the exact mechanisms of action of quinazolinones remain unknown, a study in epilepsy indicated that quinazolinones can enhance the action of GABA. The main aim of this investigation was, thus, to examine the quinazolin-4(3H)-one derivatives and GABA interaction and to identify the consequence of GABA activation in epilepsy. Docking analysis was also executed to define the residues involved in quinazolinones down regulatory action on GABA.

\section{MATERIAL AND Methods}

\section{Preparation of Target Protein X-Ray Structure}

The crystal structure of the human gamma-aminobutyric acid receptor, the GABA (A) R-beta3 homopentamer (PDB ID: 4COF) was selected as the protein target downloaded from http://www.pdb.org/.

\section{Design of new Quinazolin-4(3H)-One Derivatives}

The role of the new drug development is (i) determining the lead compound, (ii) manipulating the substituent of the lead compound, and (iii) determine the list of new substituents. In this study, quinazolin-4(3H)-one is a new lead compound of the antiepileptic agent. ${ }^{[19]}$ The substituents are selected for designing new compounds. These substituents consist of $-\mathrm{NO}_{2},-\mathrm{NH}_{2},-\mathrm{CH}_{3},-\mathrm{OCH}_{3}$, $-\mathrm{OH},-\mathrm{N}\left(\mathrm{CH}_{3}\right)_{2},-\mathrm{Cl}$, and $-\mathrm{Br}$. They are substituted in the benzylidene amino group attached to the acetohydrazide side chain.

\section{Ligands Preparation}

The structures of quinazolinone derivatives Fig. 1 were drawn by using Chem Draw Ultra 8.0 (Cambridge Soft). The 2D structures of compounds were converted to the 3D structure utilizing Chem 3D Ultra 8.0. The optimization of molecules and minimization geometry of the ligands was performed using MMFF 94 methods and saved as PBD format, to be read by the AutoDock Vina program.

\section{Molecular Docking Studies}

Molecular docking is the computational simulation of a ligand binding to a receptor, which helps to predict binding molecule to the protein target in order to predict the affinity and activity. The study of quinazoline derivatives and GABA interaction were evaluated by using molecular docking techniques on AutoDock Vina version 1.1.2. We used the crystal structure of human GABAa (code 4COF, http://www.pdb.org/) as the protein target. Prior to screening the ligands, the docking protocol was validated by re-docking the $4 \mathrm{COF}$ ligand into its binding pocket within the GABAa crystal to obtain the docked pose and root-mean-square distance (RMSD).

\section{RESULTS AND DISCUSSION}

Virtual screening experiments are the most convenient way to incorporate protein in the docking process by performing docking, using an ensemble of static receptor conformations. Molecular docking is used in modern drug design to help understand the interaction between ligands and receptors. These techniques are supported to the design of novel drug which has specific activity by the mechanism of drug-receptor interaction. Computer-aided drug design (CAAD) helps to identify small molecules by orienting and scoring them in the active binding site of a protein. The docking simulation technique was performed by using AutoDock Vina version 1.1.2 with quinazolinone derivatives and they were docked with GABAa as protein target. This program selected the best docked based on two criteria, such as, ligand binding position and fitness function scores comparison. The parameter to identify the best ligand binding position was the RMSD.

A docking score is a value that reflects the binding energy required to form a bond between the ligand and receptor, which predicts the activity of compounds. It also causes the bond between the ligand and the receptor to be more stable. The binding energy value of quinazolinones is shown in Table 1 . Twenty quinazolinone derivatives showed the approximate docking score of -7.1 to $-9.3 \mathrm{kcal} / \mathrm{mol}$. All twenty quinazolinone derivatives which value, have a greater docking score compared to diazepam used as a standard compound. Derivative Q-18 had higher binding energy than other quinazolinone derivatives because it has the smallest docking score $(-9.3 \mathrm{kcal} / \mathrm{mol})$.

All quinazolinone derivatives have hydrogen bond interaction with protein residue. The derivatives 3 and 15 have similar interactions with diazepam in a hydrogen bond with protein residue (Val E-50). One of them which has the lower docking score is compound Q-18. Compound Q-18 was substituted propyl moiety at C-2 and 2-hydroxybenzyledeneamino attached to acetohydrazide at $\mathrm{N}-3$. This means it has higher binding energy to interact

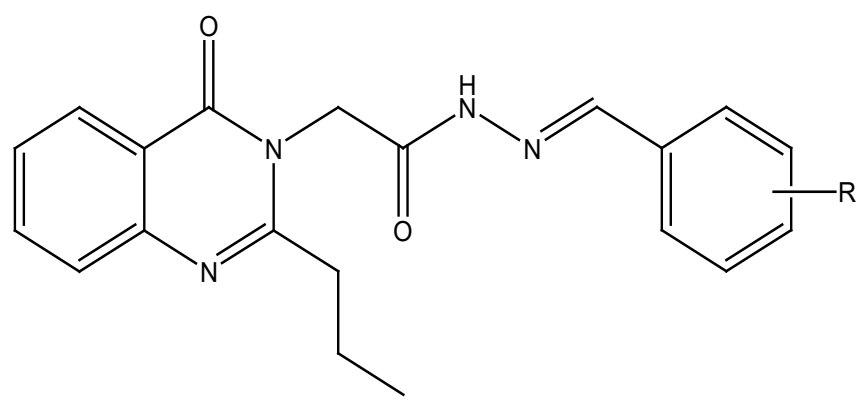

Fig. 1: General structure of quinazolin-4(3H)-one derivatives 
Surajmal Malpani et al.

Table 1: Docking score of quinazolinone derivatives with GABA

\begin{tabular}{|c|c|c|c|c|c|}
\hline Derivative & $R$ & Docking score & Derivative & $R$ & Docking score \\
\hline Q-1 & $-\mathrm{H}$ & -8.4 & Q-11 & 4-NH($\left(\mathrm{CH}_{3}\right)_{2}$ & -8.6 \\
\hline$Q-2$ & $4-\mathrm{NO}_{2}$ & -7.1 & Q-12 & 2,4-dimethoxy & -7.8 \\
\hline$Q-3$ & $4-\mathrm{NH}_{2}$ & -8.4 & $\mathrm{Q}-13$ & 2,5-dimethoxy & -8.5 \\
\hline Q-4 & $4-\mathrm{Cl}$ & -8.1 & Q-14 & 3,4,5-trimethoxy & -8 \\
\hline$Q-5$ & $4-\mathrm{OCH}_{3}$ & -8.9 & Q-15 & $2-\mathrm{NO}_{2}$ & -8.3 \\
\hline Q-6 & $4-\mathrm{CH}_{3}$ & -8.7 & Q-16 & $2-\mathrm{NH}_{2}$ & -9.1 \\
\hline Q-7 & $4-\mathrm{Br}$ & -8.2 & Q-17 & $2-\mathrm{Br}$ & -8.1 \\
\hline Q-8 & $4-\mathrm{OH}$ & -8.4 & Q-18 & $2-\mathrm{OH}$ & -9.3 \\
\hline Q-9 & $4-\mathrm{C}_{2} \mathrm{H}_{5}$ & -8.9 & Q-19 & $4-\mathrm{CF}_{3}$ & -9 \\
\hline$Q-10$ & 4-iPr & -8.9 & $Q-20$ & 2-Furyl & -7.9 \\
\hline Diazepam & Std & -7 & - & - & - \\
\hline
\end{tabular}

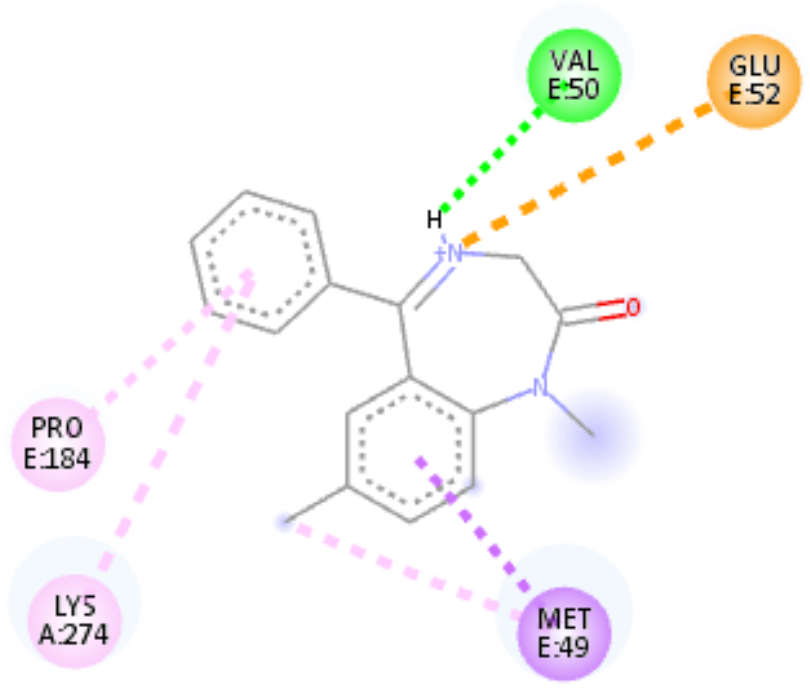

Fig. 2: 2D structure of diazepam interact with GABA

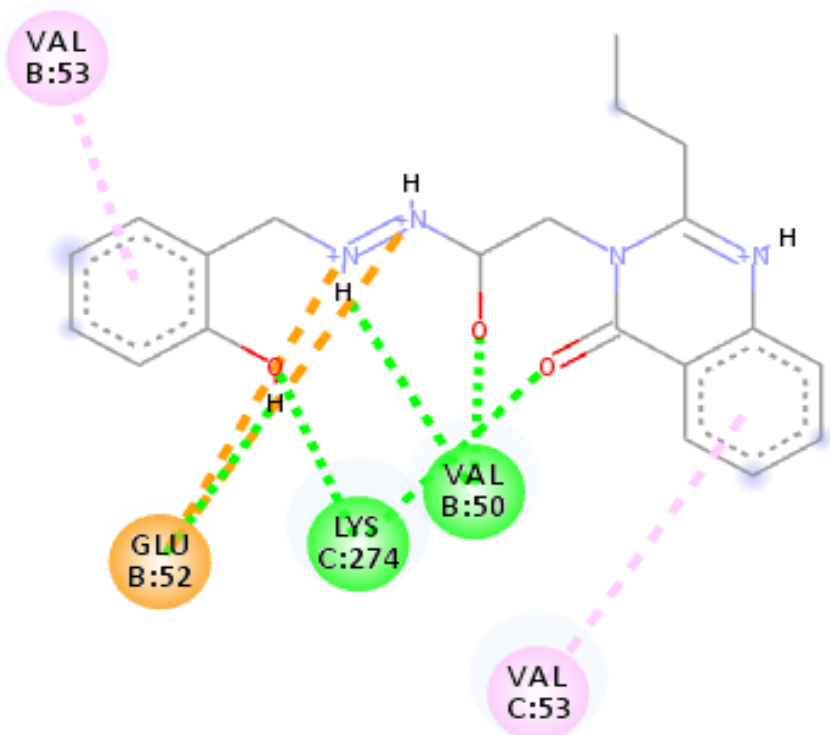

Fig. 3: 2D structure of Q-18 interact with GABA with the target receptor. The interaction compound diazepam and hydrogen bonds are shown in Fig. 2 and Q-18 in Fig. 3.

\section{CONCLUSION}

Twenty molecular structure of 3-disubstituted-4-3(H)quinazolinones, possessing propyl moiety, bound in position- 2 and substituted benzyledeneamino attached to acetohydrazide in position-3 have been docked and score obtained to identify the ligands that bind to GABAa protein structure. The result shows that all derivatives showed a higher docking score than diazepam. It means they have higher binding energy interaction with the target receptor. Therefore, these compounds could be considered potent GABAergic molecules. For further investigation, synthesis and in vitro evaluation are required to get antiepileptic activity.

\section{REFERENCES}

1. Shorvon S. Handbook of epilepsy treatment, 3rd Edition. Blackwell Science, MA (2010):1-32.

2. Guimarães J, and Ribeiro JAM. Pharmacology of antiepileptic drugs in clinical practice. The neurologist. 2010;16:353-357

3. Vitaku E, Smith DT, Njardarson JT. Analysis of the Structural Diversity, Substitution Patterns, and Frequency of Nitrogen Heterocycles among U.S. FDA Approved Pharmaceuticals. J. Med. Chem. 2014;57(24):10257-10274.

4. Witt A, Bergman J. Recent Developments in the Field of Quinazoline Chemistry. Curr Org Chem. 2003:7(7):659-677.

5. Archana, Srivastava VK, Kumar A.Synthesis of newer thiadiazolyland thiazolidinonyl quinazolin-4(3H)-ones as potential anticonvulsant agents. Eur J Med Chem. 2002;37(11):873-882.

6. Chapleo CB, Mayer M, Myer PL, Saville JF, Smith ACB, Stilling MR, et al. Substituted 1,3,4-thiadiazoles with anticonvulsant activity. 1 Hydrazines. J Med Chem. 1986;29:2273-2280.

7. Archana,Srivastava VK, Kumar A. Synthesis of some newer derivatives of substituted quinazolinonyl-2-oxo/thiobarbituric acid as potent anticonvulsant agents. Bioorg Med Chem. 2004; 12(5):1257-1264.

8. Ergenc N, Buyuktimkin S, Capan G, Baktir G, Rollas S. Quinazolinones. 19. Communication [1]: Synthesis and Evaluation of Some CNS Depressant Properties of 3-(2-[(5-aryl-1,3,4-oxadiazole-2-yl) amino]acetamido)-2-methyl-4(3H)-quinazolinones. Pharmazie. 1991;46(4):290-291. 
9. Kashaw SK, Kashaw V, Mishra P, Jain NK. Design, synthesis and potential CNS activity of some novel 1-(4-substituted-phenyl)3-(4-oxo-2-propyl-4H-quinazolin-3-yl)-urea. Arkivoc. 2008 Jan $1 ; 14: 17-26$.

10. Bekhit AA, Khalil MA. Non-steroidal anti-inflammatory agents: synthesis of novel benzopyrazolyl, benzoxazolyl and quinazolinyl derivatives of 4 (3 H)-quinazolinones. Die Pharmazie. 1998 Aug;53(8):539-543.

11. Alafeefy AM, Kadi AA, El-Azab AS, Abdel-Hamide SG, Daba MH. Synthesis, Analgesic and Anti-Inflammatory Evaluation of Some New 3H-quinazolin-4-one Derivatives. Arch Pharm (Weinheim). 2008; 341(6): 377-385.

12. Kumar A, Sharma S, Archana A, Bajaj K, Panwar H, Singh T, et al. Some New 2,3,6-trisubstituted Quinazolinones as Potent AntiInflammatory, Analgesic and COX-II Inhibitors. Bioorg Med Chem. 2003; 11(23):5293-5299.

13. Alagarsamy V, Solomon VR, Dhanabal K. Synthesis and Pharmacological Evaluation of Some 3-phenyl-2-substituted3Hquinazolin-4-one as Analgesic, Anti-Inflammatory Agents. Bioorg Med Chem. 2007; 15(1): 235-241.

14. Aziza MA, Ibrahim MK, El-Helpy AG, Al-Azhar. Design, synthesis and antiviral activity of novel quinazolinones. J. Pharm. Sci. 1994; 14: 193-201.
15. Al-Omary FA, Abou-Zeid LA, Nagi MN, El-Habib SE, AbdelAziz AA, El-Azab AS, Abdel-Hamide SG, Al-Omar MA, AlObaid AM, El-Subbagh HI. Non-classical Antifolates. Part 2: Synthesis, Biological Evaluation, and molecular Modeling Study of Some New 2,6-substituted-quinazolin-4-ones. Bioorg Med Chem. 2010; 18(8): 2849-2863.

16. Al-Obaid AM,Abdel-HamideSG, El-KashefHA, Abdel-Aziz AA, El-Azab AS, Al-Khamees HA, El-Subbagh HI. Substituted Quinazolines, Part 3. Synthesis, in vitro Antitumor Activity and molecular Modeling Study of Certain 2-thieno-4(3H)-quinazolinone Analogs. Eur J Med Chem. 2009; 44(6): 2379-2391.

17. El-Azab AS, Al-Omar MA, Abdel-Aziz AA, Abdel-Aziz NI, ElSayed MA, Aleisa AM, Sayed-Ahmed mm, Abdel-Hamid SG. Design, Synthesis and Biological Evaluation of Novel Quinazoline Derivatives as Potential Antitumor Agents: molecular Docking Study. Eur J Med Chem. 2010; 45(9): 4188-4198.

18. Al-Omar MA, Abdel-Hamide SG, Al-Khamees HA, El-Subbagh $\mathrm{H}$. Synthesis and Biological Screening of Some New Substituted-3HQuinazolin-4-one Analogs as Antimicrobial Agents. Saudi. Pharm. J. 2004; 12(2): 63-71.

19. Georgey H,Abdel-Gawad N and Abbas S. Synthesis and Anticonvulsant Activity of some quinazolin-4(3H)-one Derivatives. molecules. 2008;13:2557-2569.

HOW TO CITE THIS ARTICLE: Malpani S, Mohanty PK, Jain A. Molecular docking study of Quinazolin-4(3H)-One derivatives against GABAa receptor signifies the novel approach to epilepsy treatment. Int. J. Pharm. Sci. Drug Res. 2020;12(5):572-575. DOI: 10.25004/IJPSDR.2020.120521 